\title{
A justiça das instituições sociais Uma crítica da reconstrução normativa de $O$ direito da Liberdade de Axel Honneth
}

\author{
The justice of social institutions \\ A critique of Axel Honneth's Freedom's Right \\ normative reconstruction
}

Thiago Aguiar Simim*

\begin{abstract}
Resumo: Este texto tem como propósito analisar a construção crítica teórica de Axel Honneth das instituições sociais como efetivação da liberdade social que oferece condições para a autorrealização e a justiça. O método do trabalho consiste em se realizar a leitura interna do desenvolvimento na obra do autor à luz de sua consonância com a teoria crítica. Como conclusão discute-se em que medida o progresso moral dessas instituições se relaciona com a efetivação de seu princípio interno, de forma imanente, ou de uma pressão externa normativa da igualdade a partir do direito e da democracia.
\end{abstract}

Palavras-chave: Instituições sociais. Justiça. Reconhecimento. Liberdade social. Axel Honneth.

Abstract: The objective of this article is to analyze Axel Honneth's theoretical critical construction of social institutions as actualization of the social freedom which provides conditions to self-realization and justice. Its method consists in an internal reading of the development of Honneth's work and in the light of its consonance with critical theory. In conclusion, the article discusses to what extent the moral progress of these institutions is related immanently with the actualization of their internal principle or externally with a normative pressure of equality coming from law and democracy.

Keywords: Social institutions. Justice. Recognition. Social freedom. Axel Honneth.

\footnotetext{
* Doutorando no PPG em Direito da Universidade Federal de Minas Gerais (UFMG, Belo Horizonte, MG, Brasil), professor substituto na mesma universidade<thiagosimim@gmail.com>.
} 


\section{A reatualização indireta da Filosofia do direito de Hegel}

A obra tardia de Honneth, entendida no período de sua produção entre Sofrimento de indeterminação (2007 [2001]) e o livro O direito da liberdade (2011), ${ }^{1}$ tem duas marcas importantes: de se voltar à obra madura de Hegel e à ideia de patologia social inicial da teoria crítica. Essas características apontam para a intenção de observar criticamente as instituições sociais a partir de uma reconstrução interna dos seus princípios, aliando o projeto crítico à leitura de Hegel.

Sendo assim, Honneth dá atenção à Filosofia do direito de Hegel, revisando expressamente a afirmação de que somente os escritos do jovem Hegel seriam importantes para redescrever as esferas da eticidade formal; que somente eles dariam atenção às relações intersubjetivas de reconhecimento. Negando essa interpretação inicial da obra de Hegel, Honneth esboça sua concepção de teoria da justiça contemporânea a partir da reatualização da Filosofia do direito.

Já em Sofrimento de indeterminação (2007 [2001]), Honneth defende a possibilidade de leitura da Filosofia do direito de Hegel a partir de sua reatualização indireta, discutindo os motivos de se fazer uma leitura não sistemática do filósofo. Por "reatualização" entende-se analisar o pensamento de um filósofo do passado, como Hegel, a partir de problemas do presente (Werle e Melo, 2007). Para tanto, Honneth comenta duas formas de se levar a cabo este plano: indireta e diretamente. Uma reatualização direta deve ter como esforço uma tentativa de leitura mais fiel ao sistema filosófico do qual faz leitura. Isso significaria, na leitura que Honneth faz de Hegel, subordinar a liberdade individual à autoridade ética do estado e estruturar sua obra em sua maneira lógica - no sentido da Lógica hegeliana -, o que seria um "retrocesso nos padrões pós-metafísicos de racionalidade" (Werle e Melo, 2007, p. 33). Já a reatualização indireta, defendida pelo autor, ao invés de prezar pela integridade do sistema filosófico em questão, tem como finalidade reconstruir alguns conceitos em detrimento de outros, como forma de empregá-los em problemas e debates atuais. Para Honneth a reatualização indireta é a forma de leitura que pode fazer o hegelianismo dar frutos na filosofia política e na teoria social hoje, notadamente no debate contemporâneo em teoria da justiça.

\footnotetext{
${ }^{1}$ Não desconsideramos aqui a posição de textos intermediários. Trata-se, por outro lado, de pensar no Direito da liberdade (2011) como último momento da obra de Honneth e execução do projeto traçado em Sofrimento de indeterminação (2001).
} 
A finalidade desta reatualização indireta é trazer de forma mais crítica o conceito de justiça de Hegel para discussão em um debate já saturado com kantianos construtivistas, sem cair necessariamente nas premissas comunitaristas: de princípios de justiça não deduzidos em abstrato e a priori, mas encontrados nas práticas institucionais já existentes na realidade. $\mathrm{O}$ pano de fundo da teoria da justiça honnethiana é uma concepção crítica de que "toda a realidade social possui uma estrutura racional" (Werle e Melo, 2007, p. 36), de que é possível reconstruir fragmentos de racionalidades presentes na realidade social, pressuposto que, segundo Honneth (2007), seria compartilhado por toda a tradição da teoria crítica. O que sustenta a hipótese de Honneth, de que haveria uma racionalidade inscrita na realidade, é a remissão ao espírito objetivo em Hegel, entendido no sentido pós-metafísico como a história.

$\mathrm{O}$ intento crítico honnethiano comporta o risco, que o próprio autor admite, "[...] de sacrificar a própria substância da obra com o objetivo de uma arrumação entusiasta do texto" (Honneth, 2007, p. 50). Na reatualização indireta Honneth defende, então, uma leitura que preserve sim os fundamentos teóricos da filosofia de Hegel, sem que com isso precise compartilhar das mesmas conclusões do autor. Tendo reatualizado indiretamente a Filosofia do direito de Hegel, Honneth pretende, em um segundo momento, com $O$ direito da liberdade (2011), fazer uma reconstrução histórica que abarque o desenvolvimento das instituições sociais analisadas naquela obra.

\section{Reconstrução normativa das instituições sociais em $O$ direito da liberdade}

A reconstrução normativa da liberdade realizada por Honneth em $O$ direito da liberdade (2011) pode ser tomada, portanto, como um desenvolvimento da reatualização indireta de Hegel defendida em Sofrimento de indeterminação (2007). Já neste livro ele introduz os elementos hegelianos da Filosofia do direito no debate contemporâneo sobre teorias da justiça (Werle e Melo, 2007), mas só em 2011 ele desenvolve o núcleo de uma teoria da justiça que visa especificar as condições intersubjetivas de autorrealização individual, portanto, uma teoria da justiça que esteja vinculada não a modelos abstratos, mas a uma reconstrução das práticas e condições de reconhecimento já institucionalizadas, analisando as instituições sociais em um sentido amplo. Ou seja, em Sofrimento de indeterminação ele analisa o exercício da vontade livre e prepara o campo para fazer a reconstrução da liberdade, criando em $O$ direito da liberdade a mesma estrutura da Filosofia do direito de Hegel. 
A vontade livre é descrita da seguinte forma: o exercício da liberdade negativa se daria pelo direito abstrato, que é a indeterminação no mais alto grau; o segundo tipo de liberdade estaria na moralidade, caracterizada, ao contrário da primeira, pela forte determinação. A liberdade social efetiva consiste na reconciliação desses dois tipos mais elementares e, por isso, oscilaria entre as posições parciais de liberais e comunitaristas. A síntese dialética entre as liberdades jurídica e moral, entre liberdade universal e determinação, se dá na liberdade social, cunhada pelo termo ser-consigo-mesmo-no-outro [ImAnderen-bei-sich-selbst-sein], ou seja, uma liberdade no sentido cooperativo e não concorrente, um ser com e não contra.

Em Sofrimento de indeterminação Honneth afirma que nós experimentamos mais fortemente esta forma de liberdade no amor e na amizade. A passagem que Honneth almeja e ainda não realiza nesta ocasião, mas somente em $O$ direito da liberdade, é a da análise da eticidade nas instituições existentes, ou seja, a análise concreta "[d]as condições sociais ou institucionais, [que] devem ser concebidas como uma ordem social justa que permite a cada sujeito individual participar em relações comunicativas que podem ser compreendidas como expressão da própria liberdade" (Werle e Melo, 2007, p. 38). Para isso, ele precisa analisar as esferas da eticidade existentes, como Hegel teria feito, na família e relações íntimas, na sociedade civil (ou seja, no mercado) e no estado.

Aqui já aparece bem claro um abandono da abordagem do reconhecimento nos termos da luta por reconhecimento do jovem Hegel em prol da concepção de justiça que se aproxima mais do Hegel tardio, o que se confirma no texto introdutório de $O$ direito da liberdade (2011), chamado Teoria da justiça como análise da sociedade. Nele, Honneth traça qual o caminho de sua reconstrução normativa das esferas de realização da liberdade. A concepção geral hegeliana por trás da pesquisa social como teoria normativa é a chamada transcendência na imanência: de se voltar à realidade social para encontrar os princípios de justiça inscritos nas práticas das instituições existentes, como forma de efetiválos ainda mais. Trata-se mais uma vez da ideia de que há uma racionalidade interna à realidade social e da busca por fragmentos de racionalidade, como desiderato crítico da reconstrução normativa na teoria crítica de Honneth.

A estrutura de $O$ direito da liberdade é similar à da Filosofia do direito, pois a intenção é de uma reconstrução normativa da liberdade nas mesmas instituições analisadas por Hegel. Após uma atualização histórica do direito da liberdade, da liberdade negativa à social, passando pela reflexiva, Honneth trabalha com a possibilidade da liberdade, nas liberdades jurídica e moral, para tratar da efetivação da liberdade, na liberdade social. Neste ponto o autor 
trabalha com o "nós" nas instituições sociais, a saber: nas relações íntimas, nas trocas de mercado - tanto de trabalho, quanto de consumo - e na formação democrática da vontade política - no estado. Para Siep (2011), o livro de Honneth pretende defender, como sugere o título de seu artigo, que nós somos triplamente livres (Wir sind dreifach frei).

A reconstrução normativa per se não qualifica o projeto de releitura de Honneth como crítico, se ele não puder fazer diagnósticos de tempo. Por isso, parece ser necessário que, junto a esta reconstrução, Honneth trabalhe com as patologias sociais decorrentes de uma espécie de interferência no tipo de efetivação própria da liberdade social.

Portanto, em $O$ direito da liberdade (2011), Honneth trabalha com as patologias da liberdade, entendidas como espécies de patologias sociais, como ponto de ancoramento da crítica. Por isso, ele analisa falhas em diferentes esferas de liberdade, como da liberdade negativa, que tem como patologia a excessiva juridificação de todas as esferas da vida: a patologia segundo a qual todas as relações sociais se reduzem a ter ou obter direitos (Assheuer, 2012). O objetivo de um teórico crítico, porém, vai além da descrição das patologias sociais: deve-se explicar a raiz do distúrbio como caminho para projetar teoricamente a emancipação social. Como afirma Zurn (2011, p. 346), ${ }^{2}$ "[d]ito de forma simples, uma teoria crítica das patologias sociais necessita não somente de uma explicação precisa de desordens patológicas no nível de experiências pessoais, mas também de explanações sociológicas perspicazes das causas dessas distorções patológicas". A patologia da liberdade negativa é, para Honneth, decorrente de uma visão parcial de que liberdade significa sempre a ausência de obstáculos sociais e políticos externos. Esta visão de cunho liberal perderia de vista outro tipo de liberdade, a liberdade social, cujo exercício se dá com o outro e não contra ele. Para isso Honneth analisa narrativas como o filme Kramer versus Kramer, de Robert Benton, e o romance Indecisão, de Benjamin Kunkel, como expressões do funcionamento próprio dessas patologias (Honneth, 2011).

A concepção de patologia social de Honneth é, em muitos casos, bem próxima da ideia de Habermas de colonização sistêmica do mundo da vida, o que se deixar mostrar nas patologias sociais da liberdade negativa, na juridificação e na reificação, entre outras patologias. Sobre Habermas, Luiz Repa afirma que "[a]s patologias modernas típicas, as formas de alienação e violência são o resultado da expansão do sistema econômico capitalista e do sistema burocrático moderno para além do âmbito em que eles se desenvolvem

\footnotetext{
${ }^{2}$ Todas as traduções de referências estrangeiras são feitas em estilo livre pelo autor.
} 
originalmente [...]" (Repa, 2008, p. 163). No entanto, como Honneth não concorda com a divisão analítica feita por Habermas entre sistema e mundo da vida (Honneth, 2008), ele redimensiona todas as patologias no âmbito das interações sociais como falhas de socialização e não como interferência sistêmica. Por este motivo, Honneth consegue oferecer, a partir da análise das patologias sociais, um padrão normativo para a crítica. Se, por um lado, a patologia social da liberdade negativa pode ser lida habermasianamente como interferência dos imperativos sistêmicos no mundo da vida, por outro, contudo, a patologia da liberdade moral, como moralismo e terrorismo, é uma forma que não se reduz a esta leitura, pois diz respeito à expansão de um ponto de vista ético parcial para a generalidade. Ou seja, a patologia é o obstáculo ao movimento dialético entre dois momentos da liberdade, um abstrato e outro concreto, que teria como reconciliação o reconhecimento na liberdade social.

\section{Reconhecimento e reificação}

O que sintetiza a leitura de patologias sociais em Honneth parece ser a concepção que aparece em Reificação (2005); trata-se, no âmbito das relações sociais, da experiência do esquecimento do reconhecimento primário. No caso das patologias da liberdade negativa, Honneth tenta demonstrar como isso pode afetar o próprio indivíduo reificante e não somente o reificado. $\mathrm{O}$ fundo da patologia social é o mesmo: do esquecimento do reconhecimento pressuposto nas relações sociais já institucionalizadas.

Isso porque, para Honneth, o ato de reconhecer (Anerkennen) é, do ponto de vista ontogenético, anterior ao de conhecer (Erkennen). Ele tenta demonstrar isto em Teoria do reconhecimento (2003a [1993]): segundo o autor, a origem da autoconsciência tem a ver primariamente com a assunção de perspectiva normativa do outro. Para ele, uma série de exemplos positivos de relações de reconhecimento, nas quais as condições comunicativas estão satisfatoriamente completadas, poderiam ser dados. O que importa, no entanto, é demonstrar justamente quando elas são negadas, pois um exemplo positivo "nada mostra sua função central [...], enquanto que seu desaparecimento [negação de reconhecimento] é avaliado normalmente como indicador de uma patologia social, que pode resultar para os afetados no estado da "invisibilidade" (Honneth, 2003b, p. 19).

Nesse sentido é que Honneth prossegue na utilização do vínculo entre justiça e instituições sociais não somente como realização da liberdade social, mas insiste na utilização do termo reconhecimento recíproco em todos os âmbitos: na formação dos sujeitos, em suas relações sociais e na sua autorrelação prática. 
Em entrevista dada por Honneth em 2006 a Stojanov, ele define o papel fundamental do reconhecimento em sua teoria, que consiste em uma tese formalantropológica invariável, segundo a qual a integração social é dependente de padrões de reconhecimento recíproco, que se dão, nesta sociedade, nas esferas descritas. Nesse ponto, ele parece generalizar sua concepção, para afirmar logo depois que aquelas esferas descritas são esferas de nossa sociedade moderna e não categorias fisiologicamente dadas:

Invariável é a dependência da integração social de padrões de reconhecimento recíproco. Isto de fato me parece uma tese formal-antropológica. Dito de forma mais aguda: sequer podemos pensar formas de sociedade onde a vida e a sobrevivência sejam possíveis, nas quais a integração normativa não funcione através de determinados padrões ou mecanismos de reconhecimento recíproco (Honneth e Stojanov, 2006).

O problema central trazido por esta guinada na teoria de Honneth seria, segundo Siep $(2009,2011)$, a perda da categoria luta como motor do progresso moral. Levando-se em conta esta crítica de Siep a Honneth e uma mudança nos conceitos utilizados pelo autor entre 1993 e 2011, a pergunta que se coloca é o que realmente restou dos padrões de reconhecimento da Luta por reconhecimento na reconstrução de $O$ direito da liberdade. Em outra entrevista de Honneth, desta vez com Rasmus Willig (2012), uma das principais perguntas é sobre a revisão das esferas de reconhecimento entre Luta por reconhecimento e $O$ direito da liberdade, em cuja resposta o próprio Honneth demonstra uma dúvida quanto às revisões que operou. Para ele, não há uma resposta fácil, pois a sua obra mais recente tem como finalidade a reconstrução normativa das práticas e instituições da modernidade, diferentemente de seus trabalhos iniciais. Porém, haveria uma forma de relacionar as duas obras dividindo o reconhecimento em cinco níveis distintos, porém de modo mais complexo; neste caso, concebe-se uma subdivisão da terceira forma de liberdade, a social, como forma de realizar as duas primeiras liberdades - moral e jurídica. Segundo Honneth, "[c]omo se pode ver, o foco em uma análise da sociedade transformou as três formas originais de reconhecimento em cinco; mais do que isso, as duas primeiras formas precisam ser suplementadas por três outras formas, isto é, por 'práticas éticas' (sittlichen Praktiken)" (Willig e Honneth, 2012, p. 148). Isso significa que as três formas em teoria do reconhecimento se modificaram substancialmente, resultando em: (1) direito e (2) moral, de um lado - a possibilidade da liberdade - que precisam ser complementadas por práticas da vida real, institucionalizadas nas (3) relações íntimas pessoais, 
(4) no mercado e na (5) formação comunicativa da vontade política. Houve, assim, uma revisão daquelas esferas de reconhecimento, inclusive em seu funcionamento interno e nas suas inter-relações: ao invés de três níveis crescentes, teríamos dois níveis que possibilitam a liberdade (direito e moral), que deve ser efetivada nos três âmbitos sociais (relações íntimas, mercado e participação política). O que essas instituições de realização da liberdade social guardam em comum é o reconhecimento como mecanismo fundamental da existência social (Honneth e Stojanov, 2006).

Como visto, o próprio Honneth deixa transpassar a dificuldade de se relacionar essas duas obras (2003a e 2011), o que demonstra, na verdade, os reflexos de sua filiação a dois Hegels, separados pela Fenomenologia do espírito, cuja obra ainda hoje envolve um esforço teórico de unificação e sistematização. ${ }^{3}$

$\mathrm{O}$ que se pode interpretar a partir das declarações do próprio Honneth e da leitura de suas obras é que o reconhecimento foi cada vez mais se transformando em uma tese antropológica fundamental (cf. De Caux, 2015, cap. 3.1) à experiência humana, realizada de formas distintas nas instituições sociais e que o conflito moral, a categoria da luta, vai desaparecendo em prol da reconciliação oferecida pela história vindoura. É por este motivo que a luta e o conflito somem de cena neste modo de interpretar Hegel. Como afirma Celikates, "[a] tendência de estreitar a luta por reconhecimento na "procura e concordância de bases intersubjetivamente conectadas para nossas convicções' termina por eliminar o caráter da luta" (2007, p. 220). O caráter conflituoso do reconhecimento passa a ser visto como caminho de reconciliação e não como conflito insolúvel.

Uma vantagem desta revisão de Honneth em sua obra tardia é a utilidade da história para a realização de diagnósticos do tempo, uma vez que, na descrição mais detalhada das esferas da liberdade, na reconstrução normativa Honneth atenta para as respectivas formas patológicas. Segundo o próprio Honneth, “com certeza, é a conexão interna de autorrealização, de autorrelação positiva e reconhecimento recíproco, que fornece, para mim, a chave de uma fundamentação normativa tanto para o diagnóstico da patologia quanto para a teoria da justiça" (Honneth, 2004, p. 113). É nesse sentido que se pode compreender o vínculo entre reificação e desrespeito recorrente como a ligação entre o sentimento de injustiça, que impede o reconhecimento da perspectiva da experiência individual, e uma conformação social patológica da qual ele decorre, que se foca nas instituições sociais. ${ }^{3}$ Cf. Celikates (2007) sobre as leituras de Hegel nos modelos de Frankfurt, de Chicago e no
parisiense. 
A patologia social, como visto, é entendida como uma forma de subverter a lógica própria das instituições sociais, cujo funcionamento "saudável" proporcionaria o reconhecimento, pela realização da liberdade social. Em outras palavras, a patologia demonstraria a contrapelo o mecanismo de reconhecimento nas instituições sociais. Quanto a este projeto, Honneth parece se filiar bem à tradição da qual faz parte, aliando a perspectiva funcionalista a uma teoria da ação. A pergunta que se coloca é, em que medida o teor normativo interno a cada instituição foi reconstruído de modo crítico, ou seja, em que medida a construção intentada por Honneth consegue escapar de um "purismo" das instituições sociais que a tornam uma vez mais conservadoras ou a reconstroem sem ligação com a realidade atual? $\mathrm{O}$ desenvolvimento saudável das diferentes formas de realização da liberdade social se dá, afinal, pelo desenrolar de seu princípio interno, na forma da transcendência da imanência, ou a partir da pressão externa por maior inclusão, ampliação de direitos e democratização dessas instituições? Responder a estas questões é importante para se entender o que traz a justiça nas instituições sociais e, portanto, qual é a base de ancoramento da crítica.

\section{Conclusão: a (im)possibilidade da justiça das instituições sociais}

Retomando a relação entre justiça e reconhecimento dentro das instituições sociais na teoria de Honneth, torna-se necessário discutir o modo da reconstrução normativa que o autor intenta. Ou seja, de uma reconstrução que não deve redundar em um conservadorismo, pois parte da premissa, de cunho dialético-hegeliano, de que os princípios são insaturáveis e que eles não só podem, mas devem sempre ser revisitados. Pergunta-se se é possível uma leitura crítica de instituições sociais no sentido positivo, ou: em que medida a perspectiva institucionalista da justiça não deveria ser, pelo contrário, o ponto da crítica, uma vez que conforma as identidades? Para isso, a (re)construção específica que Honneth faz da instituição social do mercado é significativa do seu modelo de crítica.

A visão do mercado já aparece na discussão com Fraser, quando Honneth altera a terminologia dada à terceira esfera de reconhecimento, que até então variava entre estima social e solidariedade, para o termo mercado, que funciona com o código do desempenho diferencial [Leistung] (Fraser e Honneth, 2003). Mesmo que o mercado assuma o lugar dos valores éticos nas sociedades póstradicionais, mantém-se a lógica de que o sujeito é reconhecido na terceira esfera e adquire estima social quando contribui com suas particularidades para os objetivos sociais comuns. Isso porque a assunção do mercado como local 
da terceira esfera, nos termos da Luta por reconhecimento, não significou, para Honneth, um abandono do conceito de solidariedade. Como ele afirma na resposta às perguntas realizadas nos seminários em Potsdam em 2007, publicadas em 2008, “[...] eu não eliminaria necessariamente o conceito de solidariedade hoje para, ao invés disso, utilizar somente o conceito de desempenho diferenciado" (Honneth e Richter, 2008, p. 56-57).

É a divisão do trabalho, que, segundo Honneth, comporia um elo para responder a pergunta sobre como transpor o significado de uma contribuição valorizada individualmente ou em pequenos grupos para o âmbito social em geral, dado o fato do pluralismo. Para ele é a própria divisão do trabalho que possibilita, nas sociedades pós-tradicionais, o sentimento de cooperação e a coesão social pela solidariedade orgânica. É assim, pois, que "a divisão do trabalho pressupõe que o trabalhador, bem longe de permanecer curvado sobre a sua tarefa, não perca de vista os seus colaboradores, aja sobre eles e receba a sua influência" (Honneth, 2008, p. 62-63, citando Durkheim). Para Honneth,

O mecanismo de produção de solidariedade tem sempre, o quanto possível, também para as sociedades modernas complexas, a ideia da divisão do trabalho - e com a divisão do trabalho vem de par a experienciabilidade da contribuição dos outros para o objetivo compartilhado por nós [...]. Para mim, dá-se assim, em todo caso, a ligação entre o princípio de desempenho diferenciado e o conceito de solidariedade (Honneth e Richter, 2008, p. 61).

No entanto, levando-se em conta que a divisão do trabalho se dá hoje na esfera do mercado capitalista e não mais na ideia de sociedade civil burguesa, como então vincular o funcionalismo presente no mercado de trabalho com a ideia de solidariedade? Pois, para discutir o teor normativo da esfera do mercado, que possibilitaria a integração social, Honneth tem que explicar a mediação entre as duas racionalidades no mundo do trabalho. Em outros termos, como sobrepor teoricamente à racionalidade instrumental própria do mercado, de meios e fins, a racionalidade comunicativa? Mesmo que Honneth não aceite a distinção habermasiana, ele não nega a existência da racionalidade instrumental (Honneth, 1999). Para operar essa aproximação, condizente à sua leitura de Durkheim, Honneth precisa reforçar, portanto, sua discordância em relação à divisão analítica habermasiana entre sistema e mundo da vida, o que está expresso em seu artigo Trabalho e reconhecimento (2008). Honneth afirma que se trata de uma análise funcionalista com força de impacto normativo (2008), o que marca a sua perspectiva cunhada de funcionalismo normativista. Segundo Honneth: 
[...] ao responder a questão, se dispomos de critérios imanentes para a crítica das relações de trabalho existentes, tudo depende da decisão de analisar o mercado capitalista na perspectiva da integração sistêmica ou da integração social: se nos limitarmos à primeira perspectiva, então no mercado se revelam condições e regulamentações pré-econômicas, mas não princípios morais; mas se, ao contrário, nos deixamos orientar pela segunda perspectiva, então no mesmo mercado se revelam as implicações morais que, segundo Hegel e Durkheim, garantem seu ancoramento normativo no mundo social da vida (2008, p. 64).

Isso significa que, muito diferente de haver uma orientação normativa pré-contratual no mercado e de uma proveniência incidental de questões morais da reprodução material, os mercados de trabalho e de consumo criam, a partir da sua necessidade de funcionamento, pressupostos normativos de justificação de sua existência. A integração sistêmica precisa, para Honneth, de justificação normativa, comunicativa. Sua manutenção não pode se justificar socialmente pela necessidade de apropriação do trabalho alheio, nem pelo controle dos meios de produção e pelo ganho do mais-valor. Outros dois autores são apontados por Honneth como igualmente funcionalistas normativistas: Karl Polanyi e Talcott Parsons, que procuram o fundamento moral do mercado a partir de seu funcionamento ancorado na necessidade de assegurar a confiabilidade nas relações de troca e ganho. Segundo Honneth (2011, p. 337), "eles querem vincular o êxito das transações de mercado ao requisito de uma série de mecanismos institucionais de proteção, que têm por objetivo assegurar sua justificabilidade moral frente a todos os participantes". As concepções de moral no mercado, nesses autores, estão, portanto, bem alinhadas na forma da reconstrução normativa, pois a normatividade não recai sobre uma moral pré-contratural, mas sobre o modo de funcionamento sistêmico existente que precisaria de nase comunicativa em sua manutenção.

Apesar da aparência, Honneth afirma que o mercado de trabalho capitalista não é, por excelência, a instituição que regula a estima social. Sobre isso, ele mesmo afirma que a regulamentação moral extrínseca ao mercado é capaz de demarcar o sentido normativo de desempenho aplicável:

Para mim, o mercado de trabalho capitalista não representa o medium institucional através do qual a estima social é regulada conforme o princípio do desempenho diferenciado nas sociedades modernas. Muito antes, isso me parece, num sentido inverso, que a ideia normativa do 'mérito' ou do 'desempenho' rodeia a lei de mercado moralmente por fora, para evitar um mero ganho conforme expectativas circunstancialmente avaliadas a curto prazo. Neste 
ponto, os processos de uma desregularização forçada que nós podemos observar têm também constantemente o efeito de furar aqueles limites normativos que provêm do uso historicamente combatido do princípio do desempenho (Honneth, 2004, p. 118).

A existência de pretensões morais legítimas acerca do mercado de trabalho pode sim estar ligada à ideia de que todo trabalho tem algum status social, porque contribui com o todo, e que, portanto, deve receber alguma parte dos recursos econômico-materiais. Questiona-se, no entanto, se se pode enxergar essas mudanças sociais como advindas de um excedente de validade de princípios inscritos no próprio mercado ou se elas vêm de um controle externo necessário que limita seu real mecanismo.

Apesar da variação de conteúdo interno ao mercado, isso não redunda em um mecanismo formal distinto de reconhecimento, pois "o princípio do desempenho diferenciado e/ou da justiça do mérito [Leistungsgerechtigkeit] exige que a estima não seja distribuída de modo estritamente igual, mas sim conforme a colaboração com a qual os membros da sociedade participam do bem social comum" (Ikaheimo et al., 2004, p. 82). A contribuição para as finalidades sociais - éticas ou do mercado - continua a constituir o impulso interno para a luta por reconhecimento, como é o caso das greves, por exemplo, em que há um descompasso entre a contribuição e sua valorização econômica.

A intenção interna da greve é demonstrar a importância do trabalho de um setor para a sociedade através da sua falta, o que pode provocar uma maior valorização econômica. Uma disputa por aumento do salário não é simplesmente uma luta por bens materiais, mas um reflexo da pretensão de rearranjo da gramática moral no sentido de sua maior valorização, portanto é uma luta por reconhecimento. Neste sentido, o desempenho diferenciado enquanto código normativo do mercado serve também para a crítica de um estado de coisas desigual e da negação do reconhecimento no mundo do trabalho, pois envolve, em uma face, a contribuição à reprodução da sociedade. O problema é que, uma vez que inclusive a interação sistêmica é normativizada no conceito de funcionalismo normativista (Honneth, 2011), a discussão sobre a influência de imperativos sistêmicos desaparece de vez em prol de uma teoria social da reconstrução normativa das esferas de liberdade.

A questão para Honneth nessa reconstrução normativa do mercado capitalista não é inicialmente defender os mercados capitalistas de trabalho e de consumo como formas de reprodução material "saudáveis", mas antes utilizar estes princípios reconstruídos como parâmetros da crítica imanente. Isso significa dizer que um pressuposto das trocas mediadas pelo mercado é a maior eficiência para o aumento da produção, o que significa o esforço de 
todos em prol de um bem comum cooperativo: cada um dá a sua parte em um processo maior. Este pressuposto, no entanto, é negado pela realidade no mecanismo sistêmico que relaciona trabalho, salário e consumo, escondendo o mais-valor. O sentido inicial de cooperação, que é pressuposto normativo do mercado, não se realiza por ele mesmo.

Se a "promessa" social de cooperação pelo mercado se confundisse com a realização do seu modus operandi sistêmico, não haveria razão, segundo Honneth, para as demandas e lutas no mundo do trabalho, "pois o fato de que nas condições dadas há sofrimento e não apenas predomínio da indiferença, que há luta e exigências e não apenas reações de apatia estratégica só pode ser compreendido se o mercado seguir sendo analisado como parte do mundo social da vida" (2008, p. 65). Por isso Honneth enfrenta veementemente a separação analítica habermasiana entre as formas de racionalidade no sistema e no mundo da vida. Do mesmo modo, o mercado de consumo tem como "promessa", ou pressuposto normativo, a otimização das relações de troca no sentido de coordenar as necessidades e produções, ou da demanda à oferta de bens materiais que se necessita, e não de fazer da oferta e demanda o mecanismo instrumental de controle de ganhos individuais. Afinal de contas, se Honneth não encontra isso no mercado capitalista, de qual mercado então estamos tratando?

É a contraface sistêmica da lógica do mercado que provoca as distorções nesta esfera e que recebe legitimação no discurso da meritocracia, segundo o qual devem ser reconhecidos aqueles indivíduos que estejam mais adequados aos postos valorizados no mercado de trabalho. A meritocracia ou ideologia do mérito, como apropriação do princípio do desempenho diferenciado, é um discurso utilizado para justificar as desigualdades sociais e legitimar a dominação de classes, ao invés de servir à emancipação. Portanto, parece que o direito do trabalho e as medidas de inclusão servem, nesse sentido, de interferência externa do direito, que tem a capacidade de inserir o sentido do princípio da igualdade para forçar as outras esferas a um avanço qualitativo, pois a instituição social atual do mercado capitalista, por si só, reforçaria a lógica da reificação. Enxergar o mercado no molde honnethiano requer ou um esforço argumentativo maior ou uma reconstrução normativa de algo inexistente, como parece ser o caso.

Portanto, este tratamento que Honneth dá ao mercado capitalista, ignorando seu funcionamento por código binário e tratando a razão instrumental como simples forma patológica e estranha à instituição social do mercado, parece constituir um problema na sua leitura em relação ao diagnóstico de época apropriado. A confusão entre o que seria uma reconstrução histórica, que diz respeito à justificação do aparecimento natural-espontâneo do mercado, 
e a reconstrução normativa, sobre aquilo que é o pressuposto categorial contrafático do mercado capitalista de hoje, pode ter trazido esta nuance. De fato, como Habermas aponta (1981), o sistema é consequência históricosedimentada da racionalização das trocas dentro do mundo da vida, mas que se autonomiza ao longo de seu desenvolvimento. Nesse sentido, o sistema pode ter se separado do mundo da vida concretamente e não só analiticamente, pois adquiriu movimento e lógica próprios.

Ao ignorar este estado de coisas atual sobre o funcionamento do mercado capitalista, Honneth perde não somente a possibilidade de um diagnóstico de tempo adequado à práxis real, como também perde o potencial crítico de sua análise. Estendendo-se para as outras instituições sociais, a questão central seria: em que medida o desenvolvimento dessas instituições se deu através da realização do seu princípio interno ou através da força externa principalmente do direito e da democracia? Quando a instituição social familiar se abre para o casamento igualitário, como comenta Honneth (2011), trata-se da efetivação do seu princípio interno ou da força externa de uma concepção de igualdade política e jurídica? Não se trata aqui de reduzir tudo à esfera do direito, mas de questionar se uma instituição social concreta por si mesma está destinada à sua abertura, ou se é o contexto social que força a sua transformação como condição para que ela continue existindo.

No caso da instituição social da família, Habermas questiona que sua abertura constante "[...] não especifica, no entanto, se o mundo da vida familial se decompõe sob a crescente pressão da decisão, ou se irá transformar-se enquanto mundo da vida" (Habermas, 1990, p. 232). Se admitirmos que a constante inclusão do outro e abertura dessas instituições advêm de uma força extrínseca e que nunca se sabe quando as instituições vão, em razão disso, deixar de existir enquanto medium necessário de integração social, questionamos igualmente a possibilidade de se entender a justiça nas instituições sociais como desenrolar de seus próprios pressupostos.

Talvez a maior inovação dentro da obra de Honneth seja a atenção à esfera pública democrática como um lócus de realização da liberdade social. Em Luta por reconhecimento ele afirma que "[...] a vida pública teria de ser considerada não o resultado de uma restrição recíproca dos espaços privados da liberdade, mas, inversamente, a possibilidade de uma realização da liberdade de todos os indivíduos em particular" (Honneth, 2003a, p. 41), no entanto, a reconstrução das instituições democráticas como uma das três esferas fundamentais da liberdade social é, sem dúvida, uma importante transformação na perspectiva de sua teoria.

A questão fundamental nessa reconstrução das instituições sociais, que parecem ter sua abertura forçada por fora, pela efetivação, uma vez mais, do 
princípio moderno da igualdade, é em que medida elas conseguem manter a sua lógica interna em consonância com direito e a democracia. As transformações mais substanciais em instituições como família e mercado se deram a partir de demandas políticas que geraram direitos como casamento igualitário, por um lado, e direito do trabalho, por outro. Se for verdade que a transformação das instituições advém da injustiça interna a elas e se dá pela articulação política na esfera pública e retorna para a instituição social na forma de direitos, parece acertado dizer que há um ponto cego na concepção de crítica interna de Honneth que importa para a relação que ele estabelece entre a teoria e a práxis dessas instituições sociais.

\section{Referências}

ASSHEUER, Thomas. Wenn Philosophen Romane lesen. Coluna de Literatura do Jornal Die Zeit Online <www.zeit.de/2012/08/Philosoph-Honneth> (16 fev. 2012).

CELIKATES, Robin. Nicht versöhnt: wo bleibt der Kampf im „Kampf um Anerkennung"? In: Georg W. Bertram et al. (orgs.). Socialité et reconnaissance. Paris: L'Harmattan, 2007. p. 213-228.

DE CAUX, Luiz Philipe. Reconstrução e critica em Axel Honneth. Dissertação (Mestrado). Programa de Pós-Graduação em Filosofia, Faculdade de Filosofia e Ciências Humanas, Universidade Federal de Minas Gerais, Belo Horizonte, 2015.

FRASER, Nancy; HONNETH, Axel. Umverteilung oder Anerkennung? eine politischphilosophische Kontroverse. Frankfurt am Main: Suhrkamp, 2003.

HABERMAS, Jürgen. Theorie des kommunikativen Handelns. 2 v. Frankfurt am Main: Suhrkamp, 1981.

HABERMAS, Jürgen. Pensamento pós-metafisico: estudos filosóficos. Rio de Janeiro: Tempo Brasileiro, 1990.

HONNETH, Axel. Teoria crítica. In: Anthony Giddens; Jonathan Turner (orgs.). Teoria social hoje. São Paulo: Editora Unesp, 1999. p. 503-552.

HONNETH, Axel. Luta por reconhecimento: a gramática moral dos conflitos sociais. São Paulo: Editora 34, 2003a [Kampf um Anerkennung: zur moralischen Grammatik sozialer Konflikte. Frankfurt am Main: Suhrkamp Verlag, 1993].

HONNETH, Axel. Unsichtbarkeit: Stationen einer Theorie der Intersubjektivität. Frankfurt am Main: Suhrkamp, 2003b.

HONNETH, Axel. Antworten auf die Beiträge. In: Christoph Halbig; Michael Quante (orgs). Axel Honneth: Sozialphilosophie zwischen Kritik und Anerkennung. Münster: LiT Verlag, 2004. p. 99-121.

HONNETH, Axel. Verdinglichung: eine anerkennungstheoretische Studie. Frankfurt am Main: Suhrkamp Verlag, 2005.

HONNETH, Axel. Sofrimento de indeterminação: uma reatualização da Filosofia do direito de Hegel. São Paulo: Esfera Pública, 2007 [Leiden an Unbestimmtheit: eine Reaktualisierung der Hegelschen Rechtsphilosophie. Stuttgart: Philipp Reclam, 2001]. 
HONNETH, Axel. Trabalho e reconhecimento: tentativa de uma redefinição. Civitas, v. 8, n. 1, 2008. p. 46-67<10.15448/1984-7289.2008.1.4321>.

HONNETH, Axel. Das Ich im Wir: Studien zur Anerkennungstheorie. Frankfurt am Main: Suhrkamp, 2010.

HONNETH, Axel. Das Recht der Freiheit: Grundriß einer demokratischen Sittlichkeit. Frankfurt am Main: Suhrkamp, 2011.

HONNETH, Axel; RICHTER, Mathias. Diskussion: wo bleibt die Solitarität zum Status eines Leitbegriffs kritischer Gesellschaftstheorie und dessen Ort in der Anerkennung theorie von Axel Honneth. In: Christoph Menke; Juliane Rebentisch (org.). Axel Honneth, Gerechtigkeit und Gesellschaft. Postdamer Seminar, 2008. p. 47-67.

HONNETH, Axel.; STOJANOV, Krassimir. Die Anerkennung ist ein Grundmechanismus sozialer Existenz: Interview von Krassimir Stojanov mit Axel Honneth. Eurozine, $2006<\mathrm{http}$ //www.eurozine.com/articles/2006-12-08-honneth-de.html> (10 dez. 2015).

IKAHEIMO, Heikki; LAITINEN, Arto; QUANTE, Michael. Leistungsgerechtigkeit: Ein Prinzip der Anerkennung für kulturelle Besonderheiten? In: Christoph Halbig; Michael Quante (org.). Axel Honneth: Sozialphilosophie zwischen Kritik und Anerkennung. Münster: LiT Verlag, 2004. p. 81-85.

REPA, Luiz. Jürgen Habermas e o modelo reconstrutivo de teoria crítica. In: Marcos Nobre (org.). Curso livre de teoria crítica. Campinas: Papirus, 2008. p. 161-182.

SIEP, Ludwig. Kampf um Anerkennung bei Hegel und Honneth. In: Rainer et al. Forst (orgs.). Sozialphilosophie und Kritik. Axel Honneth zum 60. Geburtstag. Frankfurt am Main: Suhrkamp, 2009. p. 179-201.

SIEP, Ludwig. Wir sind dreifach frei. Coluna de Filosofia do Jornal Die Zeit Online <www.zeit.de/2011/34/L-S-Honneth> (20 ago. 2011).

WERLE, Denilson; MELO, Rúrion. Introdução: teoria crítica, teorias da justiça e a reatualização de Hegel. In: Axel Honneth. Sofrimento de indeterminação: uma reatualização da Filosofia do direito de Hegel. São Paulo: Esfera Pública, 2007. p. 7-44.

WILLIG, Rasmus; HONNETH, Axel. Grammatology of modern recognition orders: an interview with Axel Honneth. Distinktion: Scandinavian Journal of Social Theory, v. 13, n. 1, p. 145-149, $2012<10.1080 / 1600910 X .2012 .648740>$.

ZURN, Christopher. Social patologies as second-order disorders. In: Axel Honneth; Danielle Petherbridge (org.). Axel Honneth: critical essays - with a reply by Axel Honneth. Leiden: Brill, 2011. p. 345-370.

Recebido em: 30 abr. 2015

Aprovado em: 1으. 2015

Autor correspondente:

Thiago Aguiar Simim

Av. João Pinheiro, 100 - Sala dos Professores

30170-000 Belo Horizonte, MG, Brasil 